\title{
Diffuse Cerebral Calcification due to Iatrogenic Hypoparathyroidism
} İyatrojenik Hipoparatiroidiye Bağlı Yaygın Serebral Kalsifikasyon

Keywords: Hypoparathyroidism, cerebral calcification, epilepsy

Anahtar Kelimeler: Hipoparatiroidizm, serebral kalsifikasyon, epilepsi

\section{Dear Editor,}

A 63-year-old woman was evaluated in the emergency department for generalized tonic clonic seizure lasting 2-3 minutes, which was accompanied by contractions in her body and urinary incontinence. She gave a history of similar convulsions for the last 15 years, eight of which were clustered in the last year. She also reported that she sometimes had numbness, a tingling sensation in her hands and face, and cramps and weakness in her legs. She had a history of thyroidectomy for multinodular goiter 32 years ago, after which she had only rare health checks and used her medications irregularly. She had no neuropsychiatric signs, gait disturbance, or family history for any disease. Her physical examination and neurologic examination were normal. Her laboratory examination revealed normal blood count, hepatic and renal functions. She had hypocalcemia $(4.3 \mathrm{mg} /$ $\mathrm{dL})$, hyperphosphatemia $(5.4 \mathrm{mg} / \mathrm{dL})$, a low parathormone level $(2.7$ $\mathrm{pg} / \mathrm{mL})$, normal thyroid-stimulating hormone $(3.3 \mathrm{uIU} / \mathrm{mL})$, free T3 $(2.9 \mathrm{pg} / \mathrm{mL})$, free T4 (1.1 ng/dL), and vitamin D $(23.9 \mathrm{ng} / \mathrm{mL})$ levels. An electroencephalograph study was normal. Computerized brain tomography (CT) revealed diffuse symmetrical areas of calcification bilaterally in the centrum semiovale, corona radiata, periventricular white matter, caudate nucleus, putamen, globus pallidus, thalamus, and cerebellum (Figure 1,2). On brain magnetic resonance imaging (MRI), T1A sequences showed peripheral hyperintense heterogeneous areas in the caudate nucleus, putamen, and globus pallidus, and hyperintense areas in the posterior thalamus (Figure 3); T2A sequences showed hypointense heterogeneous areas in the caudate nucleus, putamen, and globus pallidus, and hyperintense heterogeneous lesions in the centrum semiovale and corona radiata (Figure 4). The patient was administered parenteral calcium replacement in the acute period, and calcium $1000 \mathrm{mg} /$ day and calcitriol $0.5 \mathrm{mcg} /$ day were begun as maintenance therapy. Her calcium level was normalized at follow-up, and she experienced no recurrent seizure attacks.

Cerebral calcification is a common condition in neurologic practice, with $0.3 \%$ to $1.5 \%$ of cases being physiologic (1). The differential diagnosis includes hereditary disorders (Fahr disease, tuberosclerosis, Cockayne syndrome, mitochondrial disorders), endocrinologic disorders, metabolic disorders (disorders of calcium, vitamin D, and iron metabolism), infections (brucella, toxoplasmosis, rubella, cytomegalovirus), and toxins (2). Hypoparathyroidism following thyroid gland surgery is one of the most common pathologic causes of cerebral calcification. As well as general symptoms such as tingling sensation, cramps, spasm, weakness, bronchospasm, and cardiac arrhythmias, the disorder may also manifest itself with seizure, altered consciousness, psychiatric, extrapyramidal, and cognitive symptoms (3). MRI is the most sensitive method for demonstrating brain lesions. However, CT is superior to MRI in detecting calcifications and determining their location. The diffuseness of calcifications depends on metabolic state, disease duration, and calcium level. Although cerebral calcification associated with hypoparathyroidism has already been reported, we deemed the diffuseness of the lesions of our case worth reporting.

\footnotetext{
Address for Correspondence/Yazışma Adresi: Şenay Yıldız Çelik MD, Zonguldak Ataturk State Hospital, Clinic of Neurology, Zonguldak, Turkey Phone: +90 5375585758 E-mail: drsenayy@gmail.com ORCID ID: orcid.org/0000-0002-7861-1018

Received/Geliş Tarihi: 14.10.2016 Accepted/Kabul Tarihi: 09.12.2016

${ }^{\circ}$ Copyright 2017 by Turkish Neurological Society

Turkish Journal of Neurology published by Galenos Publishing House.
} 


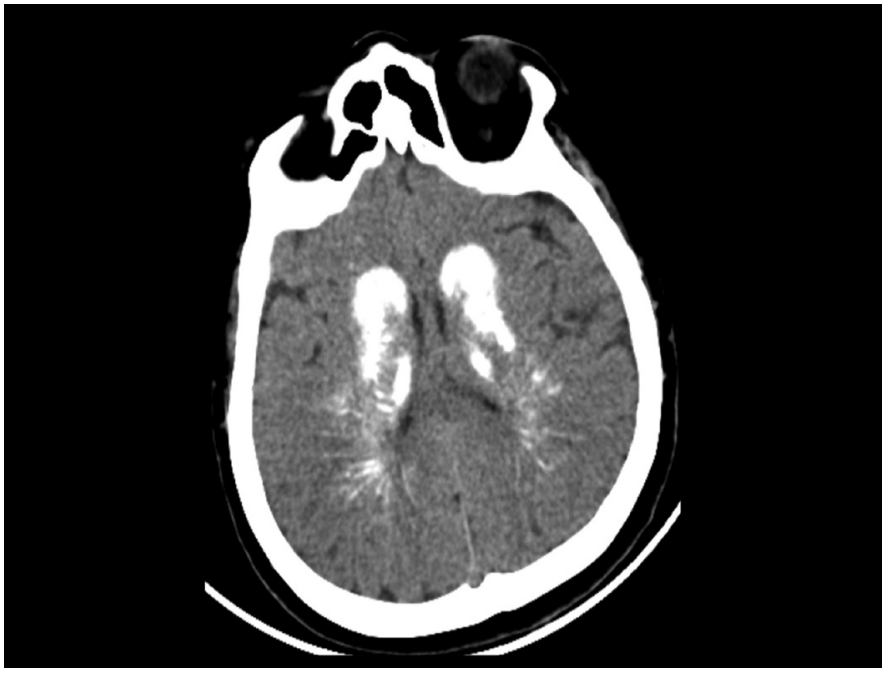

Figure 1. Bilateral diffuse symmetrical areas of calcification in the periventricular white matter, caudate nucleus, putamen, globus pallidus and thalamus on computed tomography.

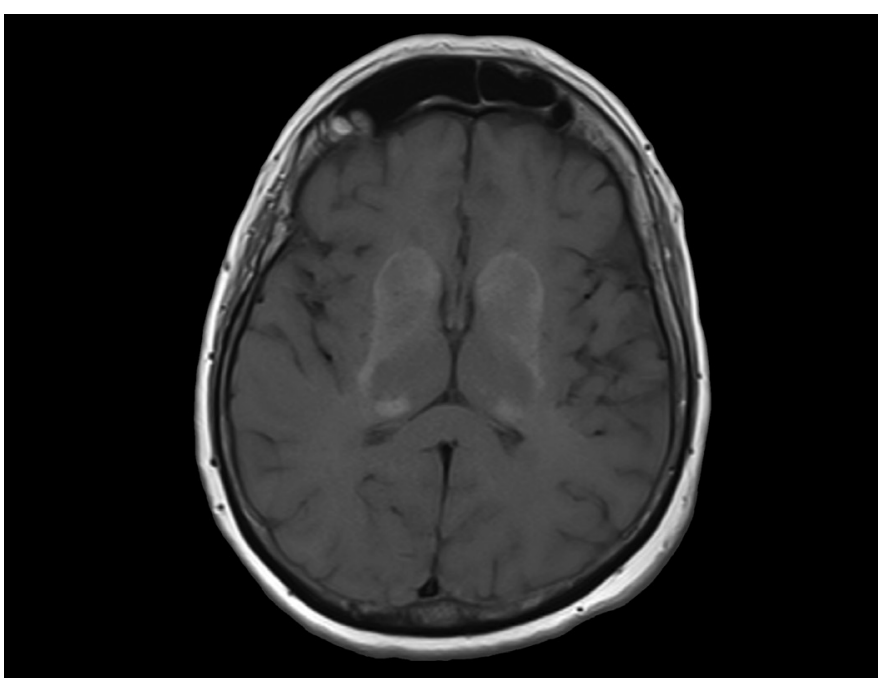

Figure 3. On $\mathrm{T} 1 \mathrm{~A}$ sequence of magnetic resonance imaging, there are peripheral hyperintense heterogeneous areas in the caudate nucleus, putamen, and globus pallidus; and a hyperintense area in the posterior thalamus.

\section{Ethics}

Informed Consent: Consent forms were completed by all participants.

Peer-review: Internally peer-reviewed.

\section{Authorship Contributions}

Surgical and Medical Practices: Ş.Y.Ç., D.Ç., Concept: Ş.Y.Ç., Design: Ş.Y.Ç., D.Ç., Data Collection or Processing: Ş.Y.Ç., Analysis or Interpretation: Ş.Y.Ç., Literature Search: Ş.Y.Ç., D.Ç., Writing: Ş.Y.Ç.

Conflict of Interest: No conflict of interest was declared by the authors.

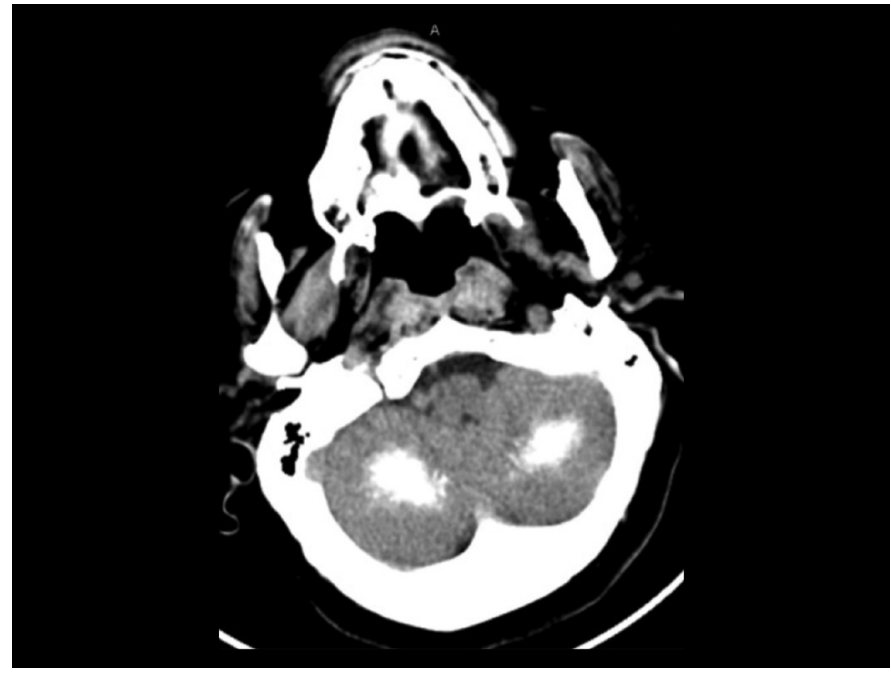

Figure 2. Bilateral diffuse symmetrical areas of calcification in cerebellum on computed tomography.

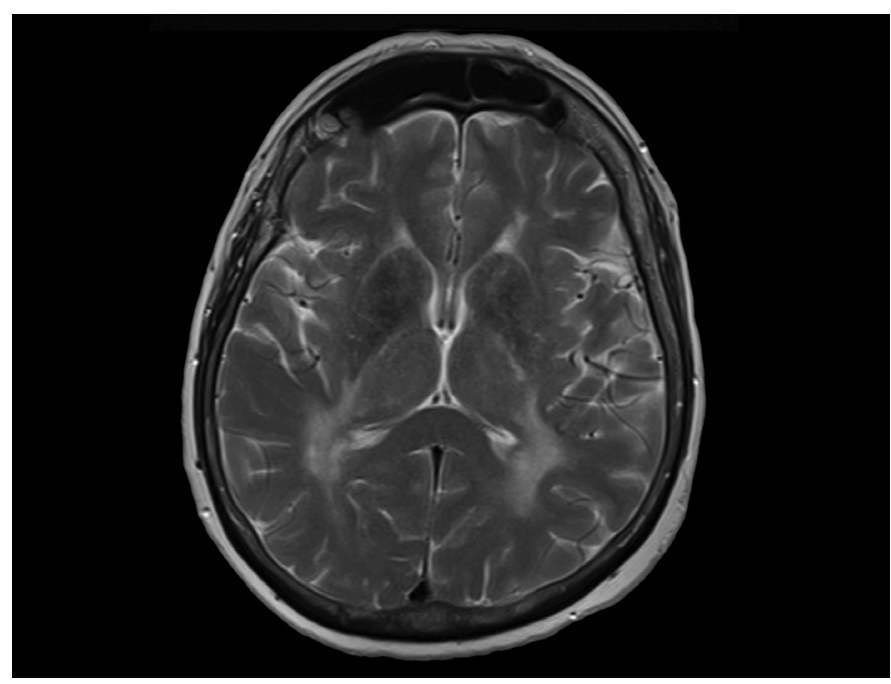

Figure 4. On T2A sequence of magnetic resonance imaging, there are heterogeneous hypointense appearances in the caudate nucleus, putamen, and globus pallidus.

Financial Disclosure: The authors declared that this study received no financial support.

\section{References}

1. Verulashvili IV, Glonti LSh, Miminoshvili DK, Maniia MN, Mdivani KS. Basal ganglia calcification: clinical manifestations and diagnostic evaluation. Georgian Med News 2006;140:39-43.

2. Saleem S, Aslam HM, Anwar M, Anwar S, Saleem M, Saleem A, Rehmani MA. Fahr's syndrome: literature review of current evidence. Orphanet J Rare Dis $2013 ; 8: 156$.

3. Rizvi I, Ansari NA, Beg M, Shamim MD. Widespread intracranial calcification, seizures and extrapyramidal manifestations in a case of hypoparathyroidism. N Am J Med Sci 2012;4:369-372. 